\title{
MENTAL SHIFT TOWARDS SYSTEMS THINKING SKILLS IN COMPUTER SCIENCE
}

\section{Stanislava Mildeová, Martin Dalihod, Anna Exnarová}

\section{Abstract}

When seeking solutions to current problems in the field of computer science - and other fields - we encounter situations where traditional approaches no longer bring the desired results. Our cognitive skills also limit the implementation of reliable mental simulation within the basic set of relations. The world around us is becoming more complex and mutually interdependent, and this is reflected in the demands on computer support. Thus, in today's education and science in the field of computer science and all other disciplines and areas of life need to address the issue of the paradigm shift, which is generally accepted by experts. The goal of the paper is to present the systems thinking that facilitates and extends the understanding of the world through relations and linkages. Moreover, the paper introduces the essence of systems thinking and the possibilities to achieve mental a shift toward systems thinking skills. At the same time, the link between systems thinking and functional literacy is presented.

We adopted the "Bathtub Test" from the variety of systems thinking tests that allow people to assess the understanding of basic systemic concepts, in order to assess the level of systems thinking. University students (potential information managers) were the examined subjects of the examination of systems thinking that was conducted over a longer time period and whose aim was to determine the status of systems thinking. . The paper demonstrates that some pedagogical concepts and activities, in our case the subject
University of Economics, Prague

mildeova@vse.cz

\section{ARTICLE INFO}

Article type

Full research paper

doi: 10.7160/eriesj.2012.050103

Article history

Received: November 12, 2011

Received in revised form: December 27, 2011

Accepted: January 23, 2012

Available on-line: March 31, 20112

of System Dynamics that leads to the appropriate integration of systems thinking in education. There is some evidence that basic knowledge of system dynamics and systems thinking principles will affect students, and their thinking will contribute to an improved approach to solving problems of computer science both in theory and practice.

\section{Key Words}

Paradigm, systems thinking, information manager, bathtub test, system dynamics, functional literacy

Mildeová, S., Dalihod, M., Exnarová, A. (2012) “Mental Shift Towards Systems Thinking Skills in Computer Science", Journal on Efficiency and Responsibility in Education and Science, Vol. 5, No. 1, pp. 25-35, ISSN 1803-1617, [on-line] www.eriesjournal.com/_papers/article_165.pdf [2012-03-31]. doi: 10.7160/eriesj.2012.050103 


\section{Introduction}

Today's world is automatically drawn together in the pursuit of information society, knowledge society or e-society, among others, but also in the experienced changes of the social paradigm that affects all disciplines and areas of life.

The aim of this paper is to contribute to the expert multidisciplinary discussion and provide some impulses for reflections on the question whether it is already time to shift the paradigm in education and science, while emphasizing the area of information technology education. Our feeling is that the socalled hard science, particularly natural sciences, is profoundly changing its approach to knowledge and understanding of objective reality. We want to highlight the need to respond to the changing situation of today's world in social science disciplines as well, especially in computer science. We focus on the need for global thinking necessary for understanding today's problems. To achieve this goal we are transforming the current framework of thinking into a systems thinking framework. We would like to put forth the general principles on which the ability of systems thinking is based, with options to achieve a mental shift towards systems thinking skills.

Various approaches are used for education in the field of informatics (see Turcani, M., Kapusta, J., 2008). Our research question that is answered in the paper deals with the degree of systems thinking of future information managers (currently students). Information management is shown by Doucek and Novotny (2007) as activities focused on managing of all information assets used by an enterprise. We performed a longterm research; its aim was to determine the overall status of systems thinking of the students (potential information managers) and to find out whether it is possible to positively influence their abilities. Measuring systems thinking skills of the students is included in the objectives of the System Dynamics course at the University of Economics in Prague (VSE). These tests are presented to students in two stages: at the beginning of the semester, before any systems thinking and any system dynamics principles were discussed, and then at the end of the semester after completing the System Dynamics course. Thus we administered the tasks twice, and compared the outcomes to test the hypothesis that following a course on system dynamics would improve the basic system thinking skills of our students.

Our research was carried out in last five years, between 2007 and 2011 (Exnarova, Dalihod and Mildeova, 2011). As regards the target group of students involved in research: study participants were 386 undergraduate students ${ }^{1}$ with specialization Information Management in the University of Economics, Prague, enrolled on an System Dynamics course (almost in seven study semester). Approximately a quarter of them were female and three-fourths of them were male.

This study that is based on our original research on the grounds of testing. The paper summarizes and enlarges results of long time systematic work of the author's collective. Classical methods of research are applied, including induction and deduction; survey and basic statistical analysis of collected data and information (advanced statistical techniques weren't applied); the Synected Gordon method for comparing domestic and international results; synthesis towards a generalization of results and contribution to pedagogical process. Thus, both empirical and theoretical approaches are applied during the paper's evolution.

The globally well-known and widely used bathtub test ("Bathtub Dynamics") (Sweeney and Sterman, 2000) was chosen

1 This number is relatively height in comparison with similar researches by using the Bathtub test abroad. 
as the basic method of research. The name Bathtub Test comes not just from the title of one of the tasks, but it originates from the basic principle of systems thinking and system dynamics, which is the resolution of stocks and flows. Stocks and flows serve as a basis for dynamic systems. The Bathtub Test and within mostly The task of flow of money within the framework of the Bathtub Test the knowledge of these flows and stocks on a number of queries over the given time interval, which are known as inflows and outflows. These skills, called "graphical integration" are fundamental for understanding dynamics complexity systems.

This test contains 5 tasks, which evaluate the learner's inclination toward systems thinking, as well as the ability to obtain necessary information from the graphic display, to derive the necessary information from the available data, and to solve the problem of missing information, and above all the ability to understand stocks and flows. The request on each parts of the systems thinking is matched with the necessary degree of functional literacy in the tasks.

\section{Material and Methods}

The paper is based on the need to change the traditional paradigm in education and science. The term "paradigm" is defined as an idea, attitude or opinion about the issue, and the way of solution, which is generally accepted by experts (Ulicna and Kacin, 2003). A paradigm is related to our mental models and determines how people understand the outside world. A paradigm shift is a complex process that is extremely individual and cannot be achieved by mere external action. If any individual wants to solve complex tasks successfully, they need to work on their long-term perception of the world and correct their mental models (Vojtko, 2005).
Inherently, systems thinking is a paradigm, a worldview, a shared world view and set of methods, models, skills, attitudes, and values. At the same time, a paradigm of systems thinking is influenced by the overall paradigm of society (Rosicky, 2010). The paradigm of systems thinking is based on the following principle: each of the causes is associated both with its effect and with each other in the causal loop feedback. It leads not only to understanding systems as a whole but also to a significant shift in world view (Mildeova and Vojtko, 2006). Richmond (1993) defines systems thinking as an art and the science as a tool to formulate reliable conclusions about the behavior of the system based on deep understanding of its basic structure.

According to Richmond (1993) Systems thinking involves three basic skills:

- Cause Thinking

- Closed-loop Thinking

- Operational Thinking

Cause Thinking is based on the belief that the problem that occurs in the system is caused by the system structure. Problematic behavior (behavior that causes problems and does not reflect the expected state) is more often (and incorrectly) assigned to external factors.

Closed-loop Thinking represents the second part of systems thinking; structure is the cause of its behavior and structure is determined by behavior. Causality is not unidirectional, quite on the contrary.

There is an important finding of systems thinking closely related to the two skills described above: the behavior of some structures is constantly repeating. These repeating structures system archetypes (generic structures, archetypes of behavior) make the study of complex social systems easier, and provide 
a key to the understanding of the structures (Nemcova, Mildeova, 2009).

Operational Thinking completes the process of thinking, it is comprised of stocks and flows, which are arranged through feedbacks. Flows and stocks are the basis for dynamic systems.

\section{Systems Thinking $x$ System Dynamics}

Uninitiated observers are not able to distinguish the important from the unimportant; therefore, they consider everything they see and perceive it as important. Necessarily, this results in information overload and mismanagement of mental problems. In Richmond (1993) is recommended as a way to identify relevant information and bring it to our mental capabilities by using various simulation tools. This brings us to the discipline of System Dynamics.

Systems thinking as a way of thinking is the foundation of the discipline called System dynamics, a methodology designed to address the real system problems. System dynamics is based on modelling (see Burianova, 2008).

The official website of The System Dynamics Society, an international organization devoted to encouraging the development and use of system dynamics around the world defines the relationship of systems thinking to system dynamics is defined as follows: "Systems thinking looks at exactly the same kind of systems from the same perspective. It constructs the same causal loop diagrams, but it rarely takes the additional steps of constructing and testing a computer simulation model, and testing alternative policies in the model" ${ }^{\prime 2}$.

The basic aim of using and teaching systems thinking and system dynamics is to improve understanding of dynamic complexity and the ability to recognize stocks, flows, time 2 http://www.albany.edu/cpr/sds/ delays, and feedback relationships and also to identify patterns of dynamic behavior of a system (Pala and Vennix, 2005).

The main purpose of the course System Dynamics at the University of Economics in Prague is to develop systems thinking and understanding of dynamic behavior of a system for students as future managers and give information about PC support for this process. The course acquaints students with principles of system dynamics methodology that would contribute to systems thinking development and understanding of dynamic behavior of a system. Training of learned skills and team cooperation is practiced by projects, in which are interactive learning environment simulated economic processes. See the course syllabus below:

1. Basic principles of system dynamics methodology, terminology of this discipline,

2. Complex social systems and their behavior, presentation of detail and dynamic complexity, delay, feedbacks, nonlinearity, modes of politics,

3. Mental models and learning, limits of mental models and possibilities for overcoming them by computer simulation, paradigm shift, critical systems thinking and its components, causal loops,

4. Systems archetypes - Drifting goals, Limits to success, Shifting the burden,

5. Main elements of models in simulation software Powersim,

6. Generic systems structures - positive feedback, negative feedback, oscillation, S-curve, overshoot and collapse,

7. Static and dynamic equilibrium, chaos, graphical integration,

8. Modeling of a material and an information delay, 
representation of nonlinear relations,

9. Models' testing - testing of time horizon, borders, structures, extreme conditions, sensitivity analyze,

10. Way to transformation of a model into a business flight simulator,

11. Project of team creation of system dynamics models:

- team putting together - appellation, assignment of specializations and roles in teams,

- work on a model of a firm (by specification of a problem)

- definition of the project schedule with accent to "learning", and not "teaching",

- presentation and defense of project results, evaluation of different strategies for problem solving,

- description of expectation and hypotheses, description of using strategies during model building and lessons from results.

There are similar study programs at other universities. System dynamics can be studied around the world at both the undergraduate and graduate levels, and also in non-degree executive education programs (see http://systemdynamics.org/ courses_in_sd.htm).

\section{Bathtub test}

The „Bathtub test" represents an important place among the tests of systems thinking that enable the evaluation of how people understand basic system concepts (Sweeney and Sterman, 2000, Sterman and Sweeney, 2002). As we showed, this test contains 5 tasks:
The first part of task 1 - Department Store task is focused on whether students are able to read the graph correctly. The next part examines their ability to integrate different pieces of information and tests the ability to understand stocks and flows (Sterman, 2000).

In task 2 - Manufacturing Case task students must imagine a production company. The task is to draw production behavior and to draw a graph of stock patterns (Sweeney and Sterman, 2000).

In task 3 - Cash flows the graph shows the hypothetical behavior of income and expenses. Based on this information, students are to draw the behavior of corporate accounts (Sweeney and Sterman, 2000).

In task 4 - Bathtub task students must look at the picture of a bathtub. Graph shows the hypothetical behavior of the inflow and outflow of the bathwater. Based on this information, students have to create a chart of the different volumes of water in the tub (Sweeney and Sterman, 2000).

The last test 5 - Global Warming works with the problem of global warming due to $\mathrm{CO}_{2}$ 's function as a greenhouse gas that contributes to global warming. Students are asked to imagine a hypothetical situation in which the $\mathrm{CO}_{2}$ emissions are suddenly reduced to zero, and to then draw the likely trajectory of $\mathrm{CO}_{2}$ emissions and global mean temperature (Sterman and Sweeney, 2002).

Another concept used by the authors is functional literacy. Functional literacy creates knowledge, skills, and statements that are needed for the full involvement and participation of man in the society in which he lives. It is a mark of some kind of behavior, namely the ability to understand printed information and to use it to achieve people's individual goals, to develop 
their skills and their potential. Functional literacy is shown by Palan (2004) as an ability, knowledge, and skills-set necessary to successfully carry out work - the function. Sometimes, functional literacy is defined as the ability to actively participate in today's world of information).

\section{A generalization of the results}

Upon successful completion of this course the course System Dynamics at the University of Economics in Prague, students are able to apply principles of system dynamics methodology and systems thinking skills towards understanding of dynamic behavior of a system. The development of systems thinking skills in the System Dynamics course has been designed via the three above described basic skills: Cause Thinking, Closed-loop Thinking, and Operational Thinking.

The Cause Thinking is aimed at new skill training with the use of case studies, and the case of the bathtub is one of them (see Figure 1). Students learn to abandon the traditional linear concept of cause and effect. System dynamics understands nonlinearity as one of the major features of complex social systems. (The graphical solution has proven to be the most suitable).

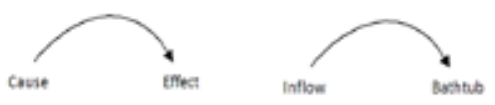

Figure 1: The Cause Thinking
The Closed-loop Thinking teaches students to organize the problem into a feedback loop. Powersim and Vensim software are used to practice this skill; students learn to create causal loop diagrams (see Figure 2). Another way in which we teach this skill is via archetypes system that helps students to understand a systems structure. At the beginning of the course students must learn the basic system archetypes. Later, students try to find some examples of these repeating structures in computer science practice. When they find these repeating structures they, are trying to find conclusions relevant for information management.

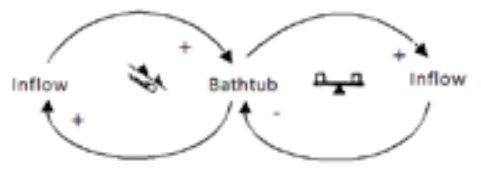

Figure 2: The Closed-loop Thinking

In the Operational Thinking students learn how to model dynamics models in the Powersim and Vensim programs (see Figure 3). With the use of these models students learn System Dynamics and practice systems thinking. 


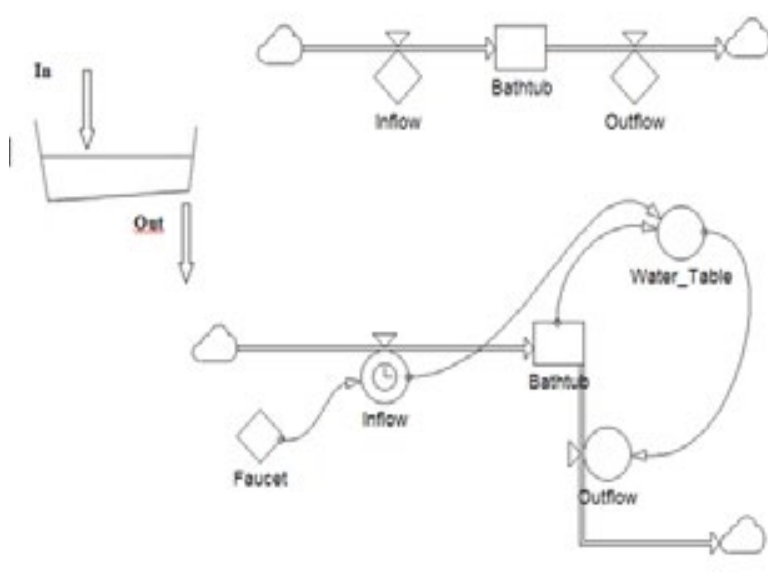

Figure 3: The Operational Thinking - from a single model to a more complex model

The reason why we use the "Bathtub Test" during the System Dynamics course is its popularity, all over the world.

The answers of the students from all tasks were coded using the criteria set by Sweeney and Sterman.

Our testing shows the existing problems in system thinking skills. In details:

The first part of Task $\mathbf{1}$ do not produce many difficulties among students. The majority of our students gave the correct answer. This shows that almost all of them can read a graph correctly and the understanding of graphic-provided information is good. The questions of the second part are dependent on proper interpretation of the flows and stocks in the system (the ability of operational thinking), and these questions posed a challenge for students.

Even considering the subjective nature of students' assessment - an allowance of which should make Task 2 relatively easy correct solutions eluded students. Unexpectedly, most of the respondents drew the curve of production counter to the curve of stocks.

The function of cash flow and bath tests knowledge about flows and stocks. Across a time interval when inflow and outflow are known, is requested in Task 3. This ability, called "graphical integration", is the basis for understanding complex dynamics systems. The results show that only half of those surveyed correctly identify the growth in the account balance, fewer students are able to place maximum and minimum in good times and draw a relationship between net flux and the account balance in the different intervals. On the other hand, most respondents correctly plot a continuous curve of the account balance.

In Task 4, the abilities to decipher required information from a graph and to integrate deciphered information (in this task, that of inflow versus outflow) are tested, as is the general functional literacy of students. Unlike the previous test, students do not have great difficulties with this task, and the success rate is relatively high.

The global warming task in Task 5 proves to be the most difficult part of the test. It requires of students skills in systems thinking, in combining information obtained from read texts, and in understanding and graphically expressing solutions. The success of solving this task is relatively small. These results shed light on students' common misunderstanding of the assignment, as many respondents expect an upward trend in 
$\mathrm{CO}_{2}$ emissions even while it should be clear that these emissions are zero.

There are no single correct solutions in some tasks, but the shapes of curves must respect certain boundaries and rules. See frequent mistakes in Task 3 shown in the picture (see Figure 4).
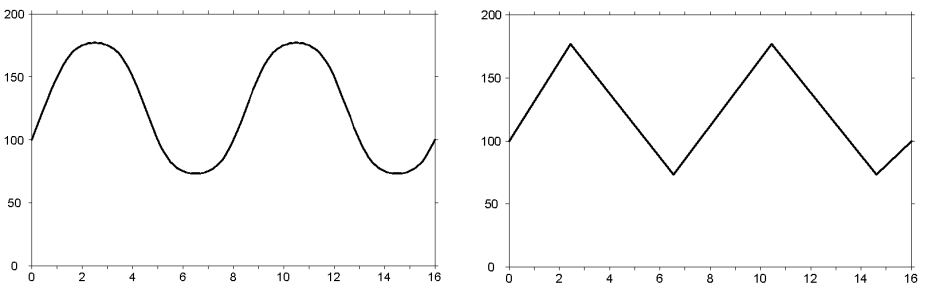

Figure 4: Correct solution (in left) and incorrect solution (in right) in Task 3

\section{Discussion}

When we compare the beginning results to the results at the end of the semester, we can see an improvement in results. The percentage of correct answers in the post-course increased and a shift from classical thinking to systems thinking can be seen. It is possible to see an enormous improvement in task 3, although students' understanding of stock and flow concepts could be even better. The general performance after the System Dynamics course is higher and can be attributed to the education they received in system dynamics principles as are stocksflows, feedback, time delays, structure-behavior relationship, and, of course, modeling. It is only in task 5 that students show only minimal improvement over the course of the semester. We can interpret this as another attempt toward other approaches to thinking which continuously changed during the semester; however, significant improvement is not achieved. And also, as pointed (Pala and Vennix, 2005), this task requires making inferences for a second-order system and problems of doing so is reflected in the results.

Regarding statistical significance and the population sample on which the research was conducted: the test is comprised of university students who represent a more-educated segment of society. We can only assume what the situation is for the population at large.

\section{A comparison to previous researches}

Various persons (researchers and teachers) used the tasks from Bathtub test at different levels (Kainz, Ossimitz, Sterman, Fisher, Heinbokel, Potash, Kubanek, Lyneis, Quaden, Ticotsky, Zaraza, Pala, Ö., Vennix, Kasperidus, H.D., Langfelder, H., Biber) before we do. Their results showed the lack of performance of the students and the systematic errors in their understanding of basic building blocks of complex systems: poor understanding of the relationship between flow and its associated stock, poor understanding of the fundamental principles such as conservation of materials, and the inability to correctly identify the behavior of a system (Pala and Vennix, 2005) and (Kasperidus, Langfelder and Biber, 2006).

The comparison of our results of testing with those in literature (Sweeney and Sterman, 2000) shows similar average performance between others (MIT) and our university. Even though the mistakes made by our students and other students (the MIT students) differ. When we compare international studies (Sweeney and Sterman, 2000) and (Pala and Vennix, 2005), the education and skills of our students are about of the same level, but this does not mean that they are at an acceptable level. It is necessary to remember that a statistically-valid 
comparison with international results cannot be completed due to a lack of knowledge of the demographic characteristics, field of study, and the students' particular level of prior education, which undoubtedly affects the ability of systems thinking.

\section{Conclusions}

Computer science is a field that affects the economy as a whole as well as individual personal lives. In this context, the paper focuses on the need for change in thinking in order to understand today's global problems, which are reflected in computer science.

Through the results based on authors' systematic data collection and measurement (for five years) we try to highlight the inadequate human mental simulation ability and the fact that the mental models that we create do not capture reality as it actually works. As a guide to improve our cognitive abilities we recommend systems thinking, which we consider as a means of understanding the world and its relations and links. Systems thinking is described in the paper as a discipline that can be used to better describe reality - to construct models of reality, estimate systems behavior, and overcome the limitations contained in mental models.

Systems thinking skills grant an important advantage to those who can handle the ability to qualitatively improved their knowledge through increasingly efficient perception of the world around them. However, one problem still remains => How do we obtain these skills?

Test results verifying the ability of systems thinking bring relatively consistent findings, and they show that human understanding does not accept the systems concept. The student performances were week and indicated systematic errors in understanding of the building blocks of complex systems. Our examination with the use of the Bathtub Test confirmed that students with systems thinking abilities were more successful in this test than students without these skills. Our experience in the System Dynamics courses leads to the conclusion that with the simulation of the System Dynamic model, students can better understand dynamic characteristics including feedback effects. Thanks to the simulation carried out in the mentioned courses, students learn to better understand the long term problems and short term problems and improve their systems thinking skills. It is a change in the style of teaching and learning tools and the paradigm of thinking. The analogous change in our thinking corresponds to the endorsed paradigm shift. This paradigm shift offers a very systematic way of thinking; a new quality emerges in synergic effect of modern systems theory and cybernetics of second order.

Understanding the text, the inclusion of general knowledge, and a systematic view of reality are still big problems for our students in the Information management specialization. As it is, after academically studying systems, these problems are reduced. We suggest that the basic information about system dynamics and systems thinking principles will affect students' thinking and will bring about better solutions to the abovementioned problems. It is not possible to teach students to think entirely differently in just 3 months. In that short time, however, you can provide basic information and options. This training should be longer-term in nature and much deeper in coverage than is the current model in the Czech school system.

At the very end it must be acknowledged that systems thinking can not be a panacea for the problems that brings the current state of computer science. It does not provide specific procedures and instructions how to solve problems. But it provides a set of 
methods and perspectives that can computer science support. Using systems thinking increases the likelihood that our interventions in the system will produce the desired results. In systems thinking we can see a way of thinking and learning.

Last but not least, it must be acknowledged that systems thinking can not be a panacea for all problems that the current state of computer science brings. It does not provide specific procedures and instructions how to solve problems. But it provides a set of methods and perspectives that computer science can support. The use of systems thinking increases the likelihood that our interventions in the system will produce the desired results. We can see a way of thinking and learning in systems thinking.

\section{Acknowledgements}

This paper is a result of institutional research project VSE IP400040 supported by Faculty of Informatics and Statistics, University of Economics, Prague.

\section{References}

Burianova, E. (2008) "Dynamic model of the collegue study sphere. Dynamic model of the collegue study sphere". Nitra: Univerzita Konstantina Filosofa Nitra, pp. 13-21. ISBN 978-80-8094-351-6.

Doucek, P. Novotny, O. (2007) "Standardy rizeni podnikove informatiky [Enterprise Informatics Management Standards]". E+M. Ekonomie a Management, Vol. X, No. 3, pp. 132-146.

Exnarova, A. Dalihod, M. Mildeova, S. (2011) "Measuring systems thinking ability". Efficiency and Responsibility in Education. Prague: Czech University of Life Sciences in Prague, pp. 66-74. Kasperidus, H.D., Langfelder, H., Biber, P. (2006). “Comparing Systems Thinking Inventory Task Performance in German
Classrooms at High School and University Level. [online], http:// www.systemdynamics.org/conferences/2006/proceed/papers/ KASPE299.pdf

Krejci, I., Kvasnička, R., Dömeova, L. (2011) "Teaching system dynamics at CULS Prague -The seminars' structure design". Efficiency and Responsibility in Education. Prague : Czech University of Life Sciences in Prague, pp. 162-170.

Mildeova, S., Vojtko, V. (2006) "Selected Chapters of System Dynamics". Bratislava : KARTPRINT, 142 p.

Pala, Ö., Vennix, J. A. M. (2005). "Effect of system dynamics education on systems thinking inventory task performance". System Dynamics Review, 21, pp. 147-172.

Palan, Z. (2004) "Funkcni gramotnost, Topregion.cz - inspirace pro rizeni rozvoje lidi $\mathrm{v}$ krajinach", [online], http://www. topregion.cz?articleId=1974.

Richmond, B. (1993) "Systems thinking: critical thinking skills for the 1990s and beyond", System Dynamics Review, Vol. 9, No. 2, New York, USA: John Wiley \& Sons, Ltd.

Rosicky, A. (2010) "Mysleni a systemovy (systemicky) pristup znalosti a mentalni modely v praxi". Systemove pristupy 2010. System Approaches 2010. Praha : Oeconomica, pp. 102-109.

Sterman, J.D. and Sweeney, L.B. (2002) "Cloudy skies: assessing public understanding of global warming". System Dynamics Review, 18(2), pp 207-240.

Sweeney, L.B. and Sterman, J.D. (2000) "Bathtub dynamics: Initial Results of a Systems Thinking Inventory". System Dynamics Review, 16(4), pp. 249-286. 
Turcani, M., Kapusta, J. (2008) "System for Adaptive Annotation of Hyperlinks in the Conditions of University Courses from the Field of Informatics", Journal on Efficiency and Responsibility in Education and Science, Vol. 1, No. 2, pp. 38-43.

Ulicna, S., Kacin, R. (2003). "Paradigm of Statistical Analysis of Economic Data", Systemove pristupy 2003. System Approaches 2003. Praha : Oeconomica, pp. 187-193.

Vojtko, V. (2005) “Co je to systémové myšlení?” [online], http:// proverbs.cz/default.asp?id=4\&mnu=4. 